\title{
Puntalama İşleminin Örülmüş Kumaşların Yapısal Özellikleri ve Hava Geçirgenliği Üzerindeki Etkilerinin Araştırılması
}

\author{
İlkan ÖZKAN ${ }^{* 1}$, Pinar DURU BAYKAL ${ }^{1}$, Yusuf KUVVETLİ ${ }^{2}$ \\ ${ }^{l}$ Ç. Ü. Mühendislik-Mimarlık Fakültesi, Tekstil Mühendisliği Bölümü, Adana \\ ${ }^{2}$ Ç.Ü. Mühendislik-Mimarlık Fakültesi, Endüstri Mühendisliği Bölümü, Adana
}

Geliş tarihi: $31.08 .2015 \quad$ Kabul tarihi: 25.12.2015

\section{Özet}

Hava geçirgenliği, kumaşların yüzey özellikleri ve yapısal parametreleri ile yakından ilgili önemli bir termal konfor parametresidir. Puntalama işlemi, basınçlı hava ile karmaşıklık vererek filamentlerin birbirlerine tutunmalarını sağlar. İplik yapısında meydana gelen bu değişim, kumaşın ilmek özelliklerini, gözenek yapısını dolayısıyla hava geçirgenliğini değiştirmektedir. Yapılan çalışma kapsamında, farklı punta sayılarına sahip polyester-POY (Partially Oriented Yarn) ipliklerden suprem kumaşlar örülmüştür. Örülen kumaşların yapısal özellikleri ve hava geçirgenlik seviyeleri test edilmiş, değişen punta sayılarının bu özellikler üzerindeki etkileri istatistiksel olarak analiz edilmiştir. Sonuç olarak, puntalama işleminin kumaş yapısında meydana getirdiği değişikliklerin hava geçirgenlik seviyesini düşürecek yönde etki ettiği görülmüştür.

Anahtar Kelimeler: Hava geçirgenliği, Punta seviyesi, Polyester POY, Örme kumaş

\section{Investigation of Effects of Intermingling Process on Structural Properties and Air Permeability of Knitted Fabrics}

\begin{abstract}
Air permeability that closely related to structural parameters and surface properties of fabrics is an important thermal comfort parameter. Intermingling process gives cohesion to the filaments with pressured air. Loop characteristics, porous structure and also air permeability of fabric are changed by the effects of intermingling process. In this study, single jersey knitted fabrics were produced by using polyester-POY (Partially Oriented Yarn) yarns having different number of nips. The structural properties and air permeability of the knitted fabric samples were measured and the effects of changing number of nips on these properties were statistically analyzed. As a result, the changes in the structure of fabrics arised from the intermingling process have an effect to reduce air permeability of fabrics.
\end{abstract}

Keywords: Air permeability, Intermingling level, Polyester POY, Knitted fabrics

\footnotetext{
* Yazışmaların yapılacağı yazar: İlkan ÖZKAN, Çukurova Üniversitesi Mühendislik Mimarlık Fakültesi, Tekstil Mühendisliği Bölümü, Adana.iozkan@cu.edu.tr
} 


\section{GİRIŞ}

Hava geçirgenliği, kumaşın birim alanından dikey yönde, birim zamanda ve belli bir basınç altında geçen havanın akış hızı olarak ifade edilir. Kumaşın hava geçirgenlik özelliği, giysi konforunu ve fonksiyonel tekstillerde kumaş performans özelliklerini etkilediğinden, tasarım aşamasında kullanım yerine bağlı olarak dikkate alınması gereken önemli özelliklerden biridir. Kumaşın hava geçirgenlik düzeyi, başta kumaşın yapısal parametrelerine bağlı olarak değişen gözeneklilik olmak üzere, sıcaklık, basınç gibi dış ortam koşullarından ve kumaş içinden geçen maddenin özelliklerinden (viskozite gibi) etkilenir [1].

Tekstil endüstrisinde tekstüre teknolojisi büyük bir öneme sahiptir. Filamentlere; hacimli yap1, iyi bir örtücülük, tuşe, 1Sı yalıtımı gibi özellikleri kazandırabilmek amaciyla tekstüre tekniklerinden faydalanılır. Mekanik tekstüre tekniklerinden olan puntalama işlemi; daha önce termomekanik tekstüre yöntemleri ile tekstüre olmuş veya olmamış filament ipliğe basınçlı hava ile karmaşıklık verilerek filamentlerin birbirlerine tutunmalarını sağlar (Şekil 1) [2]. Tekstil endüstrisinde hızla artan ekonomik kisitlar, konvansiyonel tekniklere alternatif daha ucuz yöntemlerin ortaya çıkmasını gerektirmiştir. Puntalama işlemi ise tekstüre, çekim ya da filament üretim işlemlerinde, haşıllama ve bükümde olduğu gibi filament ipliğe bir bütünlük veren alternatif bir sistem olarak türemiştir. Bunun yanında, tekstüre ve çekilmiş iplikler için yeni bir birleştirme prosesi oluşturmuştur [3].

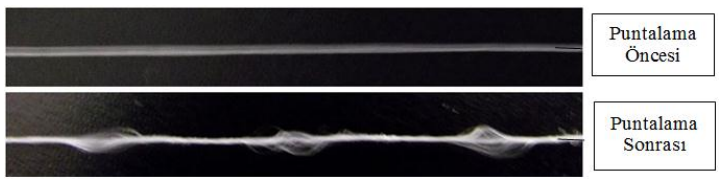

Şekil 1. Puntalama işlemi öncesinde ve sonrasında iplik görüntüsü

Şekil 1'de görüldüğü üzere puntalama işlemi sonrasında iplik yapısında bir takım değişiklikler meydana gelmekte ve bu durum kumaş gözenekliliğini de değiştirmektedir. Kumaş gözenekliliğinin değişmesi ise kumaşın hava geçirgenlik seviyesini etkilemektedir [1].

\section{2. ÖNCEKİ ÇALIŞMALAR}

Yapılan literatür araştırmasında, kumaş yapısal özelliklerindeki değişimlerin kumaş hava geçirgenliği üzerindeki etkilerini inceleyen çalışmalarla karşılaşılmış ve bu çalışmalar aşağıda özetlenmiştir.

Oğulata, dokunmuş kumaşların hava geçirgenliğini hesaplamak amacıyla kumaş yapısı, tasarımı, atkı ve çözgü sıklığı, iplik bükümü ve hacmi, gözeneklilik gibi parametreleri içeren bir teorik model üzerinde çalışmıştır. Araştırmasında hava geçirgenliği ile gözeneklilik arasında güçlü bir ilişki olduğunu, gözeneklilikteki artışın hava geçirgenliğini arttırdığını ifade etmiştir [4]. Uçar ve arkadaşları, farklı tasarımlara sahip ribana örgü kumaşların termal özelliklerini araştırmışlardır. Bu kapsamda kumaş yapısında meydana gelen sıkılaşmanın, hava geçirgenliğini azalttığını, dolayısıyla 1sı kaybını düşürdüğünü belirtmişlerdir [5]. Çay ve arkadaşları vakum kurutma sonrası dokunmuş kumaşların hava geçirgenliğini ve su miktarını tahmin etmek amaciyla bir model geliştirmeyi amaçlamışlardır. Çalışmada dokunmuş kumaşlarda hava geçirgenliğinin karmaşık bir olay olduğunu, kumaş yapısal özelliklerini esas alan tahminler için doğrusal olmayan modellerin kullanışlı olduğunu ifade etmişlerdir [6]. Afzal ve arkadaşları, örme parametrelerinin polyester/pamuk karışımı interlok örgü kumaşların hava geçirgenliği üzerindeki etkilerini tahmin etmek için istatistiksel bir model geliştirmeyi amaçlamışlardır. Çalışma kapsamında iplik karışım oranı etkisinin hava geçirgenliği üzerinde istatistiksel olarak anlamlı olmadığını, ilmek iplik uzunluğundaki azalmanın kumaşın alansal yoğunluğunu arttırdığını, bunun da hava geçirgenliğinde sert düşüşler meydana getirdiğini belirtmişlerdir [7]. Mavruz ve Oğulata, farklı numaralara sahip konvansiyonel ve kompakt ring ipliklerden, farklı ilmek uzunluklarında ürettikleri düz örme kumaşların farklı relaksasyon uygulamaları sonrası hava geçirgenliklerini 
incelemişlerdir [8]. Diğer bir çalışmada ise farklı iplik numarası, örgü tipi ve ilmek sıklığına sahip pamuklu örme kumaşların üretimden önceki hava geçirgenliği değerlerini, belirli kumaş parametreleriyle tahmin etmek amaciyla regresyon denklemleri oluşturmaya çalışılmıştır [9]. Çelik ve arkadaşları, Sirospun iplik üretiminde kullanılan eğirme metodu, hammadde, büküm katsayısı ve fitiller arası mesafenin bu ipliklerden üretilen süprem kumaşların fiziksel özelliklerine etkisini incelenmişlerdir. Çalışmada SIRO ipliklerle sarmal aralığının artmasıyla tüylülüğün azaldığı, dolayısıyla SIRO ipliklerden örülmüş kumaşların hava geçirgenliğinin ring ipliklere göre daha yüksek olduğu ifade edilmiştir [10]. Akaydın ve ark., pamuk ve viskon gibi geleneksel elyaflar ile yeni rejenere elyaflardan örme yöntemiyle üretilmiş çoraplarda, elyaf cinsinin kumaş konfor özelliklerine ve kumaş fiziksel performansına etkilerini araştırmışlardır [11]. Mezarcıöz ve arkadaşları, çalışmalarında Hesaplamalı Akışkanlar Dinamiği sistemlerini kullanarak, suprem kumaş hava geçirgenliği simülasyonu için yeni bir yaklaşım geliştirmeyi amaçlamışlardır [12]. Majumdar ve arkadaşları, pamuk, rejenere bambu ve bambu/pamuk karışımı ipliklerden farklı örgü yapılarında üretilmiş kumaşların termal konfor özelliklerini incelemişlerdir. Çalışmada, bambu liflerinin pamuk liflerinden daha küçük çapa sahip olmalarının kumaş kalınlığını ve $\mathrm{m}^{2}$ gramajını azalttığı, tüylülüğün etkisinin de pamuğa göre daha düşük olması nedeniyle iplikteki bambu miktarının artmasının hava geçirgenliğini arttırdığı ifade edilmiştir [13]. Özçelik ve arkadaşları, hava jetli tekstüre, yalancı büküm tekstüre ve tekstüre olmayan polyester filament ipliklerden üretilmiş interlok örme kumaşların termo-fizyolojik özelliklerini karşılaştırmış, ek olarak kumaş örtücülük faktörü ve hava geçirgenliğini incelemişlerdir. Çalışmada; kumaş yüzey yapıları da taramalı elektron mikroskobu kullanılarak karşılaştırılmıștır. Çalıșma sonucunda tekstüre olmayan ipliklerden üretilmiş kumaşlara kıyasla tekstüre işleminin kumaş kalınlığını arttırdığı ve hava geçirgenliğini düşürdüğü belirtilmiştir [14].

Özeti verilen literatürde, puntalı ipliklerden elde edilmiş kumaşların hava geçirgenliğinin incelendiği bir çalışmaya rastlanmamıştır. $\mathrm{Bu}$ çalışmada; puntalama işleminin kumaş yapısal parametreleri üzerindeki etkisinin ve hava geçirgenlik seviyesinde yarattığı değişimin incelenmesi hedeflenmiştir.

\section{MATERYAL ve METOT}

\subsection{Materyal}

Kısmi çekimli ve tümü dairesel kesite sahip polyester POY filamentler, çalışmada hammadde olarak kullanılmıştır. İpliklerin doğrusal yoğunluğu 283 dtex olup filament sayısı 68'dir. Filamentler üretim sonrasinda, metrede ortalama 5 adet punta olacak şekilde ön puntalama işlemine tabi tutulmuştur. Polyester POY iplikler puntalama prosesinden geçirilmiş ve 5 farklı punta sayısında iplikler elde edilmiştir (Çizelge 1). Kumaş testlerinin yapılabilmesi için bu ipliklerden, laboratuvar tipi yuvarlak örgü makinesi kullanılarak süprem örme kumaşlar üretilmiştir.

Çizelge 1. Polyester POY filament punta sayıları

\begin{tabular}{|c|c|}
\hline İplik No & Ort. Punta Sayısı \\
\hline POY (Referans) & 5,0 \\
\hline Y1 & 47 \\
\hline Y2 & 67 \\
\hline Y3 & 77 \\
\hline Y4 & 80 \\
\hline
\end{tabular}

Y: İplik numuneleri

\subsection{Metot}

Çalışmada POY bobinlerinden, farklı punta sayısına sahip iplikler üretilmiştir. Puntalama işlemi Hemaks marka HMX114 model puntalama makinesinde gerçekleştirilmiştir. Puntalama jeti olarak, Y-profilli TEMCO LD22 kullanılmıştır. Itemat Lab TSI adlı test cihazı kullanılarak, puntalanmış ipliklerin punta sayısı değerleri ölçülmüştür. Üretilen ipliklerden laboratuvar tipi yuvarlak örgü makinesi kullanılarak süprem kumaşlar üretilmiştir. $\mathrm{Bu}$ amaçla kullanılan laboratuvar tipi yuvarlak örgü makinasının teknik özellikleri Çizelge 2'de verilmiştir. Üretilen kumaşlara Çizelge 3'de isim ve standartları verilen testler uygulanmıştır. 
Çizelge 2. Laboratuvar tipi yuvarlak örgü makinesinin teknik özellikleri

\begin{tabular}{|l|l|}
\hline Örme Silindiri Çapı & 3 1/2 inç, tek kafalı \\
\hline Hız (devir sayısı) & $0-400 \mathrm{~d} / \mathrm{dk}$ \\
\hline $\begin{array}{l}\text { Makine inceliği } \\
\text { (inç'teki iğne sayıs1) }\end{array}$ & 18 adet/inç \\
\hline
\end{tabular}

Üretilen kumaşlara Çizelge 3'de isim ve standartları verilen testler uygulanmıştır.

Çizelge 3. Örme kumaşlara uygulanan testler ve standartlar1

\begin{tabular}{|c|c|}
\hline $\begin{array}{l}\text { Test Edilen } \\
\text { Özellik }\end{array}$ & Standartlar \\
\hline İlmek s1klı̆̆ & TS EN 14971 \\
\hline $\begin{array}{l}\text { Çubuk } \\
\text { siklı̆̆ } 1\end{array}$ & $\begin{array}{l}\text { Determination of number of } \\
\text { stitches per unit length and unit } \\
\text { area }\end{array}$ \\
\hline $\begin{array}{l}\text { İlmek iplik } \\
\text { uzunluğu }\end{array}$ & $\begin{array}{l}\text { TS EN } 14970 \\
\text { Determination of stitch length } \\
\text { and yarn linear density in weft } \\
\text { knitted fabrics }\end{array}$ \\
\hline $\begin{array}{l}\text { Kumaş } \mathrm{m}^{2} \\
\text { ağırlığ }\end{array}$ & $\begin{array}{l}\text { TS } 251 \\
\text { Determination of Mass Per Unit } \\
\text { Length and Mass Per Unit Area } \\
\text { of Woven Fabrics }\end{array}$ \\
\hline $\begin{array}{l}\text { Kumaş } \\
\text { kalınlığ1 }\end{array}$ & $\begin{array}{l}\text { TS } 7128 \text { EN ISO } 5084 \\
\text { Determination of thickness of } \\
\text { textiles and textile porducts }\end{array}$ \\
\hline $\begin{array}{l}\text { Hava } \\
\text { geçirgenliği }\end{array}$ & $\begin{array}{l}\text { TS } 391 \text { EN ISO } 9237 \\
\text { Determination of permeability } \\
\text { of fabrics to air }\end{array}$ \\
\hline
\end{tabular}

Kumaşlara yapılan ilmek iplik uzunluğu testinde; her kumaş numunesinden 100 adet ilmek çubuğu içerecek şekilde 10 iplik sırası sökülmüş, her bir iplik parçasının10 g ağırlık altındaki uzunlukları ölçülerek ortalamaları alınmış, elde edilen sonuç bir sıradaki ilmek sayısına bölünerek ilmek iplik uzunluğu hesaplanmıştır.

İlmek sıklığg testinde; bir lup yardımıyla kumaşın $1 \mathrm{~cm}$ uzunluğunda bulunan ilmek siraları sayılmıştır. Bu ölçüm her örnek üzerinde 5 farklı yerde tekrarlanarak, ortalaması alınmıştır. Çubuk sıklığı tespiti için ise bir lup yardımıyla kumaşın $1 \mathrm{~cm}$ genişliğinde bulunan ilmek çubukları sayılmıştır. Bu ölçüm, her örnek üzerinde 5 farklı yerde tekrarlanarak, ortalaması alınmıştır.

Kumaş kalınlığı; dijital kalınlık ölçme test cihazı ile ölçülmüştür. $\mathrm{Bu}$ işlem her kumaş örneği üzerinde 5 farklı yerde tekrarlanarak ortalama değer alınmıştır.

Kumaş $\mathrm{m}^{2}$ ağırlığı testinde; 3 farklı bölgeden alınan $100 \mathrm{~cm}^{2}$ lik kumaş numunelerinin $\mathrm{m}^{2}$ ağırlıklarının ortalaması alınarak kumaş gramajı $\left(\mathrm{g} / \mathrm{m}^{2}\right)$ hesaplanmıştır.

Elde edilen verilerin istatistiksel olarak analizinde, öncelikle parametrik istatiksel testlerin kullanılabilirliği incelenmiştir. Parametrik testlerin kullanılabilmesi için verilerin normal dağılıma uygun olması gereklidir. Ancak yapılan Kolmogorov-Smirnov testi sonucunda ölçüm sonuçlarının normal dağılıma uymadı̆̆ görülmüştür. Non-parametrik istatistiksel testler, bir hipotez testinin olasılık dağılımları gibi ek varsayımları olmadan test edilmesini sağlar [15]. $\mathrm{Bu}$ amaçla, bu çalışmada hipotezlerin değerlendirilmesinde non-parametrik test yöntemlerinden birisi olan Kruskal Wallis Tek Yönlü Varyans Analizi testi seçilmiştir. Kruskal Wallis testi iki ya da daha fazla, birbirinden bağımsız gruplar arasındaki farklılıkların istatistiksel olarak değerlendirilmesinde kullanılır. Testin temeli, ikili kıyaslamalar sonucunda tüm ölçümler için test grupları arasındaki anlamlı farklılıkları belirlemektir. $\mathrm{Bu}$ test aynı zamanda parametrik tek yönlü ANOVA analizinin nonparametrik karşılığı olarak bilinir. Bu çalışmada, istatistiksel analizler IBM SPSS paket programı yardımıyla gerçekleştirilmiştir.

\section{ARAŞTIRMA BULGULARI VE TARTIŞMA}

Kumaş testlerinden elde edilen ilmek sıklığı, çubuk sıklığı, ilmek iplik uzunluğu, gramaj, kalınlık ve hava geçirgenliği değerlerine ait sonuçlar Çizelge 4'te verilmiştir. Veri setine uygulanacak test yöntemlerinin seçiminde 
öncelikli olarak verilerin normal dağılıma uyup uymadığının belirlenmesi için KolmogorovSmirnov testi uygulanmış ve test sonuçları Çizelge 5'de verilmiştir.

Çizelge 4. Örme Kumaşlara uygulanan test sonuçları (Ortalama)

\begin{tabular}{|c|c|c|c|c|c|c|}
\hline & $\begin{array}{l}\text { İlmek } \\
\text { Sıklığ }\end{array}$ & $\begin{array}{l}\text { Çubuk } \\
\text { Siklığ } 1\end{array}$ & $\begin{array}{l}\text { İlmek } \\
\text { iplik } \\
\text { uzunluğu }\end{array}$ & Gramaj & Kalınlık & $\begin{array}{l}\text { Hava } \\
\text { Geçirgenliği }\end{array}$ \\
\hline & \multicolumn{2}{|c|}{ adet $/ \mathrm{cm}$} & $\mathrm{cm}$ & $\mathrm{gg} / \mathrm{m}^{2}$ & $\mathrm{~mm}$ & $\mathrm{~mm} / \mathrm{sn}$ \\
\hline POY & 8,60 & 8,60 & 0,56 & 86 & 0,30 & 2156,09 \\
\hline $\mathrm{K} 1$ & 8,60 & 11,20 & 0,55 & 127 & 0,38 & 1462,01 \\
\hline $\mathrm{K} 2$ & 9,00 & 11,40 & 0,54 & 125 & 0,46 & 1320,82 \\
\hline $\mathrm{K} 3$ & 8,80 & 11,60 & 0,55 & 122 & 0,47 & 1332,20 \\
\hline $\mathrm{K} 4$ & 8,80 & 11,60 & 0,55 & 127 & 0,47 & 1309,43 \\
\hline
\end{tabular}

Çizelge 5. Kolmogorov - Simirnov testi sonuçları

\begin{tabular}{|c|c|c|c|c|c|c|c|}
\hline & $\begin{array}{l}\text { Punta } \\
\text { saysa }\end{array}$ & $\begin{array}{c}\text { Hava } \\
\text { gec. }\end{array}$ & $\begin{array}{l}\text { Cubuk } \\
\text { Siliğ }\end{array}$ & $\begin{array}{l}\text { IImek } \\
\text { Uz }\end{array}$ & Gramaj & Kalmik \\
\hline \multicolumn{2}{|c|}{ Ölçüm sayısı } & 50 & 50 & 50 & 50 & 50 & 50 \\
\hline Normal & Ort. & 55,2000 & 1516,1106 & 10,8800 & 0,5500 & 117,4000 & ,4160 \\
\hline Par. & St. Sp. & 27,90947 & 338,09250 & 1,16128 & 8,00639 & 15,96680 & |,0677 \\
\hline \multirow[t]{3}{*}{ Maks. } & Mutlak &, 264 &, 331 &, 409 &, 300 &, 413 &, 342 \\
\hline & Pozitif &, 187 &, 331 &, 268 &, 300 &, 274 &, 213 \\
\hline & Negatif &,- 264 &,- 218 &,- 409 &,- 300 &,- 413 &,- 342 \\
\hline \multicolumn{2}{|l|}{ K-S } & 1,865 & 2,341 & 2,889 & 2,121 & 2,923 & 2,417 \\
\hline \multicolumn{2}{|c|}{ Anlamll11k } &, 002 &, 000 &, 000 &, 000 &, 000 &, 000 \\
\hline
\end{tabular}

Çizelge 5'de görülen anlamlılık (p) değerlerinin 0,05 'den küçük olması verilerin normal dağılıma uymadığını göstermektedir. $\mathrm{Bu}$ nedenle gruplar arası farklılıkların belirlenmesinde Kruskal-Wallis testi kullanılmıştır. Çizelge 6'da çubuk sayısı, ilmek uzunluğu, gramaj, kalınlık ve punta sayısı değerleri arasındaki farklılıkların hava geçirgenliği parametreleri üzerindeki etkileri için test sonuçları özetlenmiştir. Ayrıca, punta sayısının tüm parametreler üzerindeki etkisi de yine aynı teknikle incelenmiş, incelenen tüm parametrelerin değerleri arasındaki farklılıklar istatistiksel olarak anlamlı bulunmuştur (anlamlılık değerleri $\leq 0,05$ ).
Değişkenlerin değerleri arasındaki farkların punta sayısı ve hava geçirgenliği üzerindeki etkileri için ikili kıyaslamalar Çizelge 7'de verilmiştir. İkili kıyaslamalarda, anlamlılık değerinin 0,05'in altında olması iki grup arasında istatistiksel olarak anlamlı farklılıklar olduğunu gösterir. Çizelge 7'de punta sayısındaki değişimin tüm parametreler üzerindeki etkileri görülmektedir.

Çizelge 6. Gruplar arası farklılıklar için KruskalWallis Test Sonuçları

\begin{tabular}{|l|c|}
\hline $\begin{array}{l}\text { Kruskal Wallis } \\
\text { Test Sonuçları }\end{array}$ & $\begin{array}{c}\text { Hava Geçirgenliği } \\
\text { Anlamlılı Değeri }\end{array}$ \\
\hline Çubuk Sayısı & 0,000 \\
\hline İlmek Uzunluğu & 0,000 \\
\hline Gramaj & 0,000 \\
\hline Kalınlık & 0,000 \\
\hline Punta Sayısı & 0,000 \\
\hline
\end{tabular}

Değişkenlerin değerleri arasındaki farkların punta sayısı ve hava geçirgenliği üzerindeki etkileri için ikili kıyaslamalar Çizelge 7'de verilmiştir. İkili kıyaslamalarda, anlamlılık değerinin 0,05'in altında olması iki grup arasında istatistiksel olarak anlamlı farklılıklar olduğunu gösterir. Çizelge 7'de punta sayısındaki değişimin tüm parametreler üzerindeki etkileri görülmektedir.

Çizelge 7. Punta sayısı için ikili kıyaslamalar

\begin{tabular}{cccccc}
\hline \multirow{5}{*}{$\begin{array}{c}\text { Punta } \\
\text { sayıs1 } \\
\text { değerleri }\end{array}$} & $\begin{array}{c}\text { Çubuk } \\
\text { S1klı̆̆ } \\
(\mathrm{ad} / \mathrm{cm})\end{array}$ & $\begin{array}{c}\text { İlmek } \\
\text { Uzunluğu } \\
(\mathrm{cm})\end{array}$ & $\begin{array}{c}\text { Gramaj } \\
\left(\mathrm{gr} / \mathrm{m}^{2}\right)\end{array}$ & $\begin{array}{c}\text { Kalılık } \\
(\mathrm{mm})\end{array}$ & $\begin{array}{c}\text { Hava } \\
\text { Geçirgenliği } \\
(\mathrm{mm} / \mathrm{sn})\end{array}$ \\
\hline \multicolumn{5}{c}{ Anlamlılık Değerleri } \\
\hline $5-47$ & 1,000 & 0,005 & 0,000 & 1,000 & 0,406 \\
$5-67$ & 0,013 & 0,000 & 0,013 & 0,013 & 0,000 \\
$5-77$ & 0,000 & 0,005 & 1,000 & 0,000 & 0,000 \\
$5-80$ & 0,000 & 0,005 & 0,000 & 0,000 & 0,000 \\
$47-67$ & 1,000 & 0,005 & 0,160 & 1,000 & 0,082 \\
$47-77$ & 0,001 & 1,000 & 0,001 & 0,001 & 0,174 \\
$47-80$ & 0,001 & 1,000 & 1,000 & 0,001 & 0,036 \\
$67-77$ & 0,160 & 0,005 & 1,000 & 0,160 & 1,000 \\
$67-80$ & 0,160 & 0,005 & 0,160 & 0,160 & 1,000 \\
$77-80$ & 1,000 & 1,000 & 0,001 & 1,000 & 1,000 \\
\hline Kumas & &
\end{tabular}

Kumaş yapısal değişkenlerindeki (çubuk sıklığı, ilmek uzunluğu, gramaj ve kalınlık) değişimin 
Puntalama İşleminin Örülmüş Kumaşların Yapısal Özellikleri ve Hava Geçirgenliği Üzerindeki Etkilerinin Araştırılması

hava geçirgenliği üzerindeki etkileri Çizelge 8 'de görülmektedir.

Çizelge 8. Kumaş yapısal değişkenlerinin hava geçirgenliği üzerindeki etkileri

\begin{tabular}{|c|c|c|c|c|c|c|c|}
\hline $\begin{array}{l}\text { Çubuk } \\
\text { Siklı̆g } \\
\text { (ad/cm) }\end{array}$ & $\underset{\text { değeni }}{\mathrm{p}}$ & $\begin{array}{c}\text { Ilmek } \\
\text { Uzunluğu } \\
\text { (cm) }\end{array}$ & $\underset{\text { değei }}{\mathrm{p}}$ & $\begin{array}{l}\text { Gramaj } \\
\left(\mathrm{g} / \mathrm{m}^{2}\right)\end{array}$ & $\underset{\text { değei }}{\mathrm{p}}$ & $\begin{array}{c}\text { Kalmilk } \\
(\mathrm{mm})\end{array}$ & $\underset{\text { değeii }}{\mathrm{p}}$ \\
\hline $8,6-11,20$ & 0,244 & $0,54-0,55$ & 0,841 & $86-122$ & 0,000 & $0,3-0,38$ & 0,244 \\
\hline $8,6-11,40$ & 0,000 & $0,54-0,56$ & 0,000 & $86-125$ & 0,000 & $0,3-0,46$ & 0,000 \\
\hline $8,6-11,60$ & 0,000 & $0,55-0,56$ & 0,000 & $86-127$ & 0,000 & $0,3-0,47$ & 0,000 \\
\hline $\begin{array}{l}11,20- \\
11,40\end{array}$ & 0,049 & & & $122-125$ & 1,000 & $0,38-0,46$ & 0,049 \\
\hline $\begin{array}{l}11,20- \\
11,60\end{array}$ & 0,014 & & & $122-127$ & 1,000 & $0,38-0,47$ & 0,014 \\
\hline $\begin{array}{l}11,40- \\
11,60\end{array}$ & 1,000 & - & . & $125-127$ & 1,000 & $0,46-0,47$ & 1,000 \\
\hline
\end{tabular}

Buna göre, Çizelge 4 ve Çizelge 7 birlikte incelendiğinde, punta sayısında meydana gelen artışın kumaş çubuk sıklığını artırdığı görülmektedir. Bu artış 5-67, 5-77, 5-80, 47-77 ve 47-80 punta sayıları ikili karşılaştırmalarda istatistiksel olarak anlamlı bulunmuştur. POY polyester iplik, puntalandığında hacimli ve tüylü bir hal almakta (Şekil 1), bu durum da örme sırasında ipliklerin birbirine tutunarak kumaşın yapısının daha kompakt bir hal almasına neden olmaktadır. Bunun sonucunda, ilmek çubukları birbirine yaklaşmakta ve çubuk sıklığı artmaktadır. Trinoküler mikroskop ile 30x büyütme oranında alınmış kumaş görüntüleri Şekil 2' de verilmiştir.

Çizelge 4 ve 8 birlikte incelendiğinde, çubuk sıklığı değerleri arasındaki fark arttıkça hava geçirgenliği üzerinde anlamlı farklılıklar oluşmaktadır. Çubuk sıklığında meydana gelen artış, hava geçirgenliği üzerinde azaltıcı bir etki yaratmaktadır. $\mathrm{Bu}$ sonuç, önceki çalışmalarla örtüşmektedir [9].

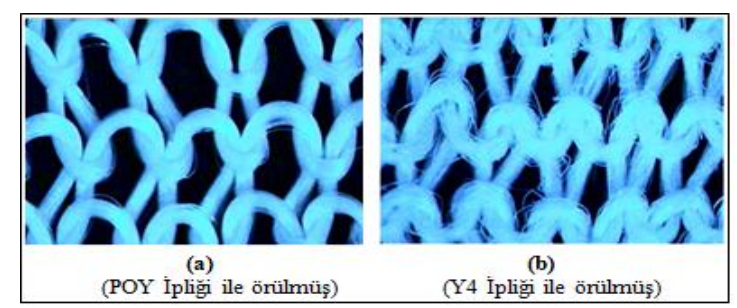

Şekil 2. Kumaş görüntüleri
İlmek uzunluğu açısından bakıldığında, punta sayısındaki artışla birlikte kumaşta meydana gelen kompakt yapı birim uzunluğa düşen ilmek sayısını artırmakta ve bu durum ilmek iplik uzunluğunun bir miktar azalmasına neden olmaktadır (Şekil 2). İstatistiksel analiz sonuçlarına göre de, POY ile tüm puntalı iplikler arasındaki farklar istatistiksel olarak anlamlı bulunmuştur. Punta sayısı arasındaki farklar azaldıkça, istatistiksel anlamlılık ortadan kalkmaktadır (Çizelge 7).

İlmek uzunluğunun hava geçirgenliğine etkisi incelendiğinde, ilmek iplik uzunluğundaki değişimin hava geçirgenliğine anlamlı bir şekilde etki ettiği görülmektedir (Çizelge 6 ve 8). İlmek iplik uzunluğu arttıkça, iplikler arasındaki gözeneklerin büyüklüğü artacağından hava geçişi fazla olacaktır [9].

İlmek uzunluğunda oluşan değişime benzer bir değişim kumaş gramajında da gözlenmektedir. Yapılan çalışmada, gramaj artışı kumaş yapısının daha kompakt bir hal almasından kaynaklanmakta ve bu yapısal değişiklik, kumaş hava geçirgenliğini düşürmektedir.

Kalınlık açısından bakıldığında, puntalama işlemi ipliğe hacim kazandırmakta ve bu hacim kalınlıkta artış olarak kumaşa yansımaktadır. İplik punta sayısı 47 üzerine çıktığında $P O Y^{\prime}$ dan örülmüş kumaş ile oluşan kalınlık farkı istatistiksel olarak anlamlı bir hal almaktadır. Ancak, punta sayıs1 arasındaki farklar azaldıkça $(67-77,67-80$ ve 77-80 punta) istatistiksel anlamlılık ortadan kalkmaktadır.

Kumaş kalınlığındaki değişim hava geçirgenliği üzerinde anlamlı değişikliklere neden olmaktadır (Çizelge 6). Bu çalışmada elde edilen sonuçlar, önceki çalışmalarla örtüşmektedir. Kumaş kalınlığı arttığında; gözeneklerde sürtünme kayıpları arttığından, basınç kayıpları artmakta, bu da havanın gözeneklerden geçişini zorlaştırmaktadır [9].

Hava geçirgenliği açısından bakıldığında, iplik yapısında meydana gelen hacimlilik ve tüylülük, hava geçirgenliğini azaltmaktadır. Benzer şekilde puntalanmış iplikten örülen kumaş yapısı punta 
sayısının artmasıyla, daha kompakt bir hal almakta, ilmek gözenekleri daralmakta bu da hava geçirgenliğini olumsuz yönde etkilemektedir. İlmek yapısındaki değişim Şekil 2'de görülmektedir. İstatistiksel analiz sonuçlarına göre de, POY ile punta sayısı 47'nin üzerinde olan ipliklerden örülmüş kumaşların hava geçirgenlik değerleri arasındaki farklar istatistiksel olarak anlamlı bulunmuştur. Kumaş hava geçirgenliğini etkileyen parametreler Şekil 3'de görülmektedir. Parametrelerin aynı grafikte gösterilebilmesi ve eğilimlerin izlenebilmesi amacıyla değerler çeşitli katsayılarla çarpılmış ve bu değerler grafikte belirtilmiştir.

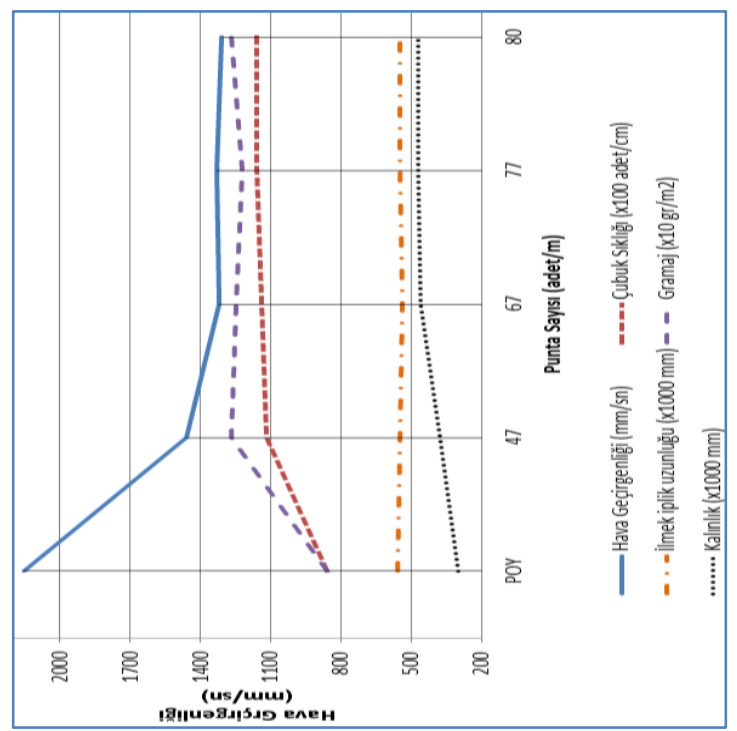

Şekil 3. Hava geçirgenliğini etkileyen parametreler

\section{SONUC}

İplik punta sayısında meydana gelen değişimin kumaş hava geçirgenliği üzerindeki etkisi incelenirken, puntalama işleminin iplik yapısında meydana getirdiği değişimler (hacimlilik ve tüylülük) ve bunların örülmüş kumaş yapısı üzerindeki etkileri bir arada değerlendirilmelidir.

Önceki çalışmalarda kumaş hava geçirgenliğine çubuk sayısı, ilmek iplik uzunluğu, gramaj ve kalınlık değerlerinin etkisi incelenmiş olmakla birlikte bu çalışmada ek olarak punta sayısındaki değişimin etkisi de incelenmiştir. Punta sayısının kumaş yapısında oluşturduğu değişim ve hava geçirgenliği etkileşimli olarak değerlendirilmiş ve sonuçlar aşağıda maddeler halinde özetlenmiştir.

- Punta sayısındaki artış iplik yapısında hacim artışı ve tüylülük meydana getirmektedir. $\mathrm{Bu}$ durum kumaş örülürken ilmek çubuklarının birbirine tutunmasına neden olmakta böylece yap1 kompakt bir hal almaktadır. Kompakt yap1 ve oluşan tüylülük, gözenekleri daraltmakta bu durum ise hava geçirgenliğinde düşüş olarak kendini göstermektedir.

- Yukarıda açıklanan yapısal değişimin etkisiyle santimetredeki çubuk sayısı artmakta, bunun bir sonucu olarak kumaş gramajı artış, hava geçirgenliği ise düşüş göstermektedir.

- Hacimli bölgeler ve yapısal daralma kumaş kalınlık değerlerinde artışa neden olmaktadır. Artan kalınlık kumaş hava geçirgenliğini düşürmektedir.

- Genel olarak, punta sayısındaki artışın ve bunun kumaş yapısında meydana getirdiği değişikliklerin kumaş hava geçirgenliği üzerinde düşürücü bir etki yarattığı ve bu etkinin istatistiksel olarak anlamlı olduğu görülmüştür.

Not: Yapılan çalışma kapsamında elde edilen sonuçların bir bölümü Romanya' da gerçekleştirilen "15th AUTEX World Textile Conference" etkinliğinde poster bildiri olarak sunulmuştur [16].

\section{KAYNAKLAR}

1. Turan, R. B., Oku, A. 2008. Kumaşlarda Hava Geçirgenliği, Tekstil ve Mühendis, 15(72), 16-25.

2. Özkan İ., Duru Baykal P., 2015. Filamentlerde Puntalama İşleminden Kaynaklanan Numara Değișimlerinin Araștırılması, Çukurova Üniversitesi Mühendislik Mimarlık Fakültesi Dergisi, 30(1), 167-173.

3. Demir, A., 2006. Sentetik Filament İplik Üretim ve Tekstüre Teknolojileri, Şan Ofset, İstanbul.

4. Ogulata, R. T., 2006. Air Permeability of Woven Fabrics. Journal of Textile and Apparel, Technology and Management, 5(2), 1-10. 
5. Uçar, N., Yılmaz, T., 2004. Thermal Properties of $1 \times 1,2 \times 2,3 \times 3$ Rib Knit Fabrics. Fibres \& Textiles in Eastern Europe, 12(3), 47.

6. Çay, A., Vassiliadis, S., Rangoussi, M., Tarakcioglu, I., 2007. Prediction of the Air Permeability of Woven Fabrics Using Neural Networks. International Journal of Clothing Science and Technology, 19(1), 18-35.

7. Afzal, A., Hussain, T., Malik, M. H., Javed, Z., 2014. Statistical Model for Predicting the Air Permeability of Polyester/Cotton-Blended Interlock Knitted Fabrics. the Journal of the Textile Institute, 105(2), 214-222.

8. Mavruz S., Ogulata R. T., 2011. Investigation of Air Permeability of Single Jersey Fabrics with Different Relaxation States, the Journal of The Textile Institute, 102:1, 57-64.

9. Mavruz S., Ogulata R. T., 2009. Pamuklu Örme Kumaşlarda Hava Geçirgenliğinin İncelenmesi ve İstatistiksel Olarak Tahminlenmesi, Tekstil ve Konfeksiyon, (1), 29-38.

10. Çelik, P., Üte, T. B., Kadoğlu, H., 2012. Comparative Analysis of the Physical Properties of the Fabrics Knitted with Sirospun and Ring Spun Yarns Produced by Short and Long Staple Fibres. Tekstil ve Konfeksiyon, 22(4), 324-331.

11. Akaydin, M., Gül, R., 2014. A Survey of Comfort Properties of Socks Produced from Cellulose-Based Fibers. Tekstil ve Konfeksiyon, 24(1), 37-46.

12. Mezarcıöz, S., Mezarciöz, S., Oğulata, R. T., 2014. Prediction of Air Permeability of Knitted Fabrics by Means of Computational Fluid Dynamics. Tekstil ve Konfeksiyon, 24(2), 202211.

13. Majumdar, A., Mukhopadhyay, S., Yadav, R., 2010. Thermal Properties of Knitted Fabrics Made from Cotton and Regenerated Bamboo Cellulosic Fibres. International Journal of Thermal Sciences, 49(10), 2042-2048.

14. Özçelik, G., Cay, A., Kirtay, E., 2007. A Study of the Thermal Properties of Textured Knitted Fabrics. Fibres \& Textiles in Eastern Europe, 15(1), 55-58.

15. Varian, Hal R., 1983. Non-Parametric Tests of Consumer Behavior, The Review of Economic Studies, 50(1), 99-110.
16. Özkan İ., Duru Baykal P., 2015. Effects of Fabrics Structural Parameters and Number of Nips on Air Permeability of Fabrics Knitted Using Intermingled Yarn, 15th AUTEX World Textile Conference, June10-12, Bükreş, Romanya. 